\title{
Susceptibility to nontuberculous mycobacterial lung disease
}

\author{
P. Sexton and A.C. Harrison
}

ABSTRACT: The nontuberculous mycobacteria (NTM) exhibit heterogeneous pathogenicity in humans. Articles on known and potential human factors capable of producing susceptibility to NTM lung disease (NTMLD) were identified by a systematic search of the medical literature, and are reviewed in the present study.

Patients with pre-existing structural lung disease are known to be at risk of NTMLD. Other susceptible groups have become recognised since the 1980s, in particular middle-aged nonsmokers without previous lung disease (a group including those with Lady Windermere syndrome) and patients with genetically determined defects of cell-mediated immunity, including abnormalities of the interleukin-12/interferon- $\gamma$ axis, certain human leukocyte antigen alleles, cystic fibrosis transmembrane conductance regulator mutations, and polymorphisms of solute carrier $11 \mathrm{~A} 1$ (or natural resistance-associated macrophage protein 1 ) and the vitamin $\mathrm{D}$ receptor.

Information is also accruing about acquired systemic causes of susceptibility to NTMLD, including inhibitory antibodies directed against interferon- $\gamma$, post-menopausal waning of endogenous oestrogen levels, coeliac disease and exposure to use of dietary phyto-oestrogens. It is not known whether immunosuppressive factors, such as oral corticosteroid treatment, chronic renal failure, diabetes mellitus and other known risk factors for pulmonary tuberculosis, are also risk factors for the development of NTMLD. Caution is appropriate in managing such patients.

KEYWORDS: Bronchiectasis, immunodeficiency, Lady Windermere syndrome, Mycobacterium avium-intracellulare complex, nontuberculous mycobacterial lung disease, susceptibility

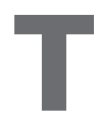
he nontuberculous mycobacteria (NTM) are a group of $>100$ species of bacteria that are ubiquitous in soil and water, and which exhibit varied pathogenicity. NTM are opportunists, requiring defects in local or systemic host immunity in order to cause disease in humans. The present study reviews the evidence relating to congenital and acquired conditions that may predispose individuals to NTM lung disease (NTMLD).

The classification of NTM has evolved, and the number of organisms involved has increased enormously. Initially, classification of mycobacteria was based on phenotype, and was limited to identification of the known pathogens, Mycobacterium tuberculosis, $M$. bovis and $M$. avium-intracellulare complex (MAC). Later, NTM were divided into four groups on the basis of pigment production and growth speed. Runyon groups I-III were slow growers and group IV contained rapid growers [1]. The early history of the classification and identification of mycobacteria has been summarised by WOLINSKY [2]

The development of 165 ribosomal DNA gene sequencing improved the accuracy of species identification and led to the description of many new mycobacterial species. However, the older phenotype-based classification system is still clinically relevant. For example, rapidly growing mycobacteria are generally less virulent than more slowly growing species [3], although their capacity for biofilm formation and tolerance of a wide range of environmental conditions contributes to their capacity to cause nosocomial disease.

\section{METHODS}

PubMed was searched for English language articles using combinations of search terms, including "Mycobacterium", "nontuberculous mycobacterium", "atypical mycobacterium", "Mycobacterium

\section{AFFILIATION}

Green Lane Respiratory Services, Auckland City Hospital, Auckland, New Zealand.

\section{CORRESPONDENCE}

A.C. Harrison

Green Lane Respiratory Services Auckland City Hospital

Park Road

Grafton

Auckland

New Zealand

Fax: 6496310712

E-mail: adrianh@adhb.govt.nz

Received:

October 232007

Accepted after revision:

January 242008

STATEMENT OF INTEREST

None declared. 
avium-intracellulare", "Lady Windermere syndrome", "bronchiectasis", "cystic fibrosis", "immunodeficiency", "immunosuppression", "susceptibility", "risk factor", "interferon gamma", "tumour necrosis factor", "human immunodeficiency virus", "transplant", "cancer" and "malignancy". The initial search identified 1,822 articles. These were screened to ensure relevance to the topic of the review. Article reference lists were then searched for additional relevant articles. Approximately 180 articles were reviewed. Information on the strength of evidence was collected from original research articles. However, estimates of risk of NTM infection and disease are less certain than in diseases such as tuberculosis (TB) because the NTM denominators are unknown in most populations.

\section{SYSTEMIC DEFENCES AGAINST MYCOBACTERIAL DISEASE}

The normal host immune response to mycobacterial infection has been described elsewhere [4,5]. Lipoarabinomannan in the mycobacterial cell wall binds to macrophage Toll-like receptor (TLR)2 [6], inducing production of the cytokines interleukin (IL)-12 and tumour necrosis factor (TNF)- $\alpha$. IL-12 binds to its receptor (IL-12R) on the surface of activated T-cells and natural killer cells. The IL-12/IL-12R complex upregulates production of interferon (IFN)- $\gamma$ via the signal transducer and activator of transcription 4 (STAT4) signalling pathway.

\section{Interferon- $\gamma$ and tumour necrosis factor- $\alpha$}

IFN- $\gamma$ is an extracellular pro-inflammatory cytokine that activates both the innate and adaptive arms of the immune system, principally in response to intracellular microbial infection. Its effects include: stimulating production of other pro-inflammatory cytokines, such as TNF- $\alpha$ and IL-12; inhibiting the production of anti-inflammatory cytokines, such as IL4; upregulating major histocompatibility complex (MHC) class II expression on the surface of macrophages and other antigenpresenting cells; stimulating immunoglobulin (Ig) production by B-lymphocytes; promoting differentiation of T-helper lymphocytes (Th) into the Th1 phenotype; and promoting apoptosis of anti-inflammatory Th2 lymphocytes [7].

IFN- $\gamma$ binds to the IFN- $\gamma$ receptor (IFN- $\gamma$ R). This receptor is a heterodimer, with IFN- $\gamma \mathrm{R} 1$ and IFN- $\gamma \mathrm{R} 2$ chains, and is present on the surface of many inflammatory cells. Binding of IFN- $\gamma$ to IFN- $\gamma \mathrm{R}$ leads to modulation of nuclear gene expression via the Janus kinase (JAK)-STAT signalling pathway as follows. JAK associated with IFN- $\gamma \mathrm{R}$ phosphorylates STAT1. This enters the nucleus, where it binds to promoter regions of IFN- $\gamma$-inducible genes [7]. The functions of these genes include promotion of MHC-I and -II expression, modulation of leukocyte-epithelial cell interactions, and promotion of inflammatory cytokine synthesis and free radical formation [8]. These functions are key aspects of the innate and acquired immune response to most microbial pathogens, and are pertinent as systemic defences against mycobacterial disease.

TNF- $\alpha$ is released by a variety of inflammatory cells, predominantly macrophages, in response to immune recognition of mycobacterial lipoarabinomannan. TNF- $\alpha$ binds to the macrophage membrane-bound TNF- $\alpha$ receptors 1 and 2 , acting through the intracellular nuclear factor (NF)- $\kappa B$ pathway to modulate gene expression $[9,10]$. TNF- $\alpha$ recruits and activates other inflammatory cells, and appears essential for granuloma formation [11]. Increased susceptibility to mycobacterial disease is a recognised side-effect of treatment with TNF- $\alpha$ antagonists [12].

\section{Mycobacterial virulence factors}

The molecular basis of mycobacterial virulence has recently been reviewed $[13,14]$. It mainly resides in the components of the cellular envelope. These include lipoarabinomannan, a polysaccharide that promotes intracellular mycobacterial survival by blocking phagosomal maturation [15]; and trehalose dimycolate (or cord factor), a glycolipid that exerts hyperinflammatory effects through modulation of IFN- $\alpha$ secretion and is implicated in cavitating disease [16]. Important secreted products include: catalase [17]; protein kinase G, which inhibits lysosomal fusion [18]; and enhanced intracellular survival protein, which inhibits T-cell proliferation in vitro [19].

The virulence of NTM varies by species but is generally low in immunocompetent individuals. Given the environmental ubiquity of NTM, either intense exposure or defects in local or systemic host immunity are probably necessary in order for disease to develop [20].

\section{SUSCEPTIBILITY TO NTMLD}

Patients with pre-existing structural lung disease are known to be at increased risk of NTMLD. Respiratory diseases associated with risk of NTMLD in multiple cross-sectional and cohort studies include chronic obstructive pulmonary disease, bronchiectasis, cystic fibrosis (CF), previous TB, silicosis, pneumoconiosis and alveolar proteinosis [21-30]. Other established risk factors for NTMLD include increasing age, male sex, smoking, alcohol abuse, residence in urban or coastal environments, and participation in mining and smelting [31]. Since the 1980s, other susceptible groups have been identified, in particular middle-aged nonsmokers without previous lung disease (a group which includes those with Lady Windermere syndrome [32]) and patients with genetic defects in cellmediated immunity. Additionally, information is accruing regarding a number of acquired systemic causes of susceptibility to NTM disease. The remainder of the present study reviews the local and systemic factors that may play a role in increasing susceptibility to NTMLD. For most of the factors discussed, table 1 outlines relevant investigations and states the level of published evidence that supports the association.

\section{Mechanical factors and impaired local immunity}

MAC infection begins when the mycobacterial virulence factor, fibronectin attachment protein, adheres to fibronectin within exposed extracellular matrix on damaged mucosal surfaces [70]. In vitro studies in human tissue show that NTM are only able to adhere to damaged mucosa, unlike $M$. tuberculosis, which adheres to intact mucosa [71]. Impairment of local immune function due to chronic pulmonary diseases and mucosal damage combine to increase propensity for NTMLD. Factors compromising local immunity include impaired clearance of secretions, abnormal composition of airway surface liquid, abnormal composition of sputum and airway damage caused by persistent inflammation [72]. Theoretically, locally impaired perfusion may lower tissue oxygenation and reduce the accessibility of blood-borne protective factors. 


\begin{tabular}{|c|c|c|}
\hline Disease & Tests & Evidence linking to NTMLD \\
\hline Cystic fibrosis & Sweat chloride, CFTR genotyping & $\begin{array}{l}\text { Cohort studies [33], case-control studies [34-39], } \\
\text { prevalence studies [40-45] }\end{array}$ \\
\hline $\begin{array}{l}\text { Deficiencies in IFN- } \gamma \mathrm{R} 1, \mathrm{IFN}-\gamma \mathrm{R} 2 \text {, } \\
\text { IL-12, IL-12R }\end{array}$ & $\begin{array}{l}\text { Tests of IFN- } \gamma \text { production in response to mycobacterial } \\
\text { antigens, other specialised immunological tests, genotyping }\end{array}$ & $\begin{array}{l}\text { Case reports and series [48-52]; no evidence for isolated } \\
\text { lung disease }\end{array}$ \\
\hline STAT1 deficiency & Tests of cellular response to exogenous IFN & Case reports $[53,54]$; no evidence for isolated lung disease \\
\hline Chronic granulomatous disease & Tests of neutrophil function (e.g. nitroblue tetrazolium) & One case report [55] \\
\hline $\begin{array}{l}\text { HLA types associated with NTM } \\
\text { disease }\end{array}$ & HLA genotyping & One prevalence study [56], one cohort study [57] \\
\hline Vitamin D deficiency & Serum vitamin D & No direct evidence \\
\hline Coeliac disease & Coeliac autoantibodies and serum IgA & No direct evidence \\
\hline HIV infection & HIV serology & $\begin{array}{l}\text { Cohort studies [63], prevalence studies [64], case series } \\
{[23,65-68]}\end{array}$ \\
\hline Inhibitory anti-IFN- $\gamma$ antibodies & Anti-IFN- $\gamma$ antibodies & One case series [69] \\
\hline
\end{tabular}

Only high-resolution computed tomography (HRCT) of the chest can be regarded as a routine clinically relevant test. Further study is required in order to determine whether or not specific indications can be found for the other tests listed. When interpreting the information regarding the type and strength of evidence for each risk factor, it should be borne in mind that the strength of association between many risk factors and NTM disease is unknown due to the lack of mandatory reporting of NTM infection. COPD: chronic obstructive pulmonary disease; TB: tuberculosis; GORD: gastro-oesophageal reflux disease; IFN- $\gamma R$ : interferon (IFN)- $\gamma$ receptor; IL: interleukin; IL-12R: interleukin-12 receptor; STAT1: signal transducer and activator of transcription 1; HLA: human leukocyte antigen; SLC11A1, soluble carrier 11A1; CFTR: cystic fibrosis transmembrane conductance regulator; $\alpha_{1}$-AT: $\alpha_{1}$-antitrypsin; VDR: vitamin D receptor; Ig: immunoglobulin.

\section{Bronchiectasis}

Bronchiectasis and NTM lung infection (NTMLI) frequently coexist, and it is often difficult to separate cause from effect. Among patients in the UK with adult-onset bronchiectasis, the prevalence of NTMLI and NTMLD have been reported at 10 and $3 \%$, respectively [24]. No difference was found in age, sex or spirometric results between patients with and without evidence of NTMLI. Peripheral mucus plugging on computed tomography (CT) was more common among patients with NTMLI. This raises the possibility that stagnant secretions provide an important medium for NTM (and other organisms) to proliferate. The present authors postulate that optimal use of airway clearance methods in bronchiectasis may protect against the development or progression of NTMLD. Although bronchiectasis is a risk factor for NTMLI and NTMLD, there is no consistent evidence that NTMLD and the severity of bronchiectasis are correlated [24, 30].

\section{Cystic fibrosis}

CF has been associated with an increased prevalence of NTMLI in several cross-sectional and cohort studies [33-45]. It is likely that the mechanisms of susceptibility in $\mathrm{CF}$ are similar to those in non-CF bronchiectasis. Peripheral mucus plugging is more common in CF than in non-CF bronchiectasis $[24,59]$.

The prevalence of NTMLI in CF has increased since the early 1990s [73]. Suggested explanations include increased testing frequency, improved sampling and culture techniques, and the increasing lifespan of CF patients, due to either decades of exposure being required to contract NTM or milder CF lung disease permitting not only longer survival but also somehow providing a more suitable environment for NTM [33].

\section{Gastro-oesophageal reflux disease}

Gastro-oesophageal reflux disease (GORD) appears to be common among patients with NTMLD [46, 47]. THOMSON et al. [46] studied 58 patients with MAC lung disease (MACLD). A clinical diagnosis of GORD was more common among patients with MACLD than among age-matched controls (44 versus $28 \%$; $<<0.019)$. Since patients with MAC were more frequently prescribed acid suppressive therapy, THOMSON et al. [46] speculated that acid suppression may increase risk of NTMLD by promoting survival of NTM in gastric fluid. However, they also point out that acid suppressive therapy may simply reflect more severe GORD.

$\mathrm{KoH}$ et al. [47] performed 24-h $\mathrm{pH}$ monitoring on 58 patients with type 2 NTMLD (MAC and M. abscessus); $26 \%$ showed evidence of GORD. Those with GORD exhibited more widespread airways disease on CT (bronchiectasis involving a median of four versus two lobes; $\mathrm{p}=0.008)$, and were more likely to show acid-fast bacilli on sputum smear ( 80 versus $44 \%$; $\mathrm{p}=0.033$ ). Only $27 \%$ of patients with NTMLD and GORD reported symptoms of reflux. 
Thus it is not clear whether GORD symptoms are simply more common among patients who cough, whether GORD is relevant only insofar as it causes airways disease which then predisposes to NTM disease, or whether reflux independently increases the risk of NTMLD, for example by delivering NTM into airways.

\section{Type 2 NTMLD and Lady Windermere syndrome}

In 1989, PRINCE et al. [74] reported a series of patients with MACLD without apparent predisposing factors; $81 \%$ of the patients were female and $76 \%$ had a radiographical pattern of fibronodular (type 2) NTMLD, rather than the classic cavitatory (type 1) pattern. It has subsequently become clear that this syndrome is also common amongst those with lung disease caused by NTM other than MAC [73]. Sufferers are usually white, female and post-menopausal [74-76]. REICH and JOHNSON [76] reported that disease commonly occurs in the right middle lobe (RML) and lingula in these individuals. They proposed that this syndrome is related to a fastidious habit of voluntary cough suppression, and named the entity Lady Windermere syndrome [32].

The validity of Lady Windermere syndrome has been challenged. Some authors have pointed out that patients with myopathy, stroke or other conditions associated with impaired cough are not at increased risk of NTMLD [77]. A history of habitual cough suppression was not reported in the patients studied by REICH and JOHNSON [76]. However, there have since been several reports in which cough suppression has been documented [78, 79]. Another question is whether or not NTMLD affects the RML and lingula more often than would be expected by chance; a study of 31 patients with type 2 MACLD by HUANG et al. [80] found no predilection for any anatomical location. REICH and JOHNSON [76] found confinement of disease to the RML or lingula in only $21 \%$ of cases, which could be due to chance [20].

There are anatomical factors that could make the RML and lingula more susceptible to NTMLD. Both locations exhibit a relative lack of collateral ventilation and have long narrow bronchi that are dependent when upright. Both are features that might impair clearance of secretions [81]. Repeated vibration from the heart (in conjunction with gravity) might also impede the clearance of secretions from these lobes.

Certain physical features appear to be more common among patients with type 2 NTMLD. These include a tall slender body habitus, pectus excavatum, scoliosis and mitral valve prolapse $[80,82,83]$. Many of these features resemble those found in inherited connective tissue disorders such as Marfan's syndrome and the phenotype associated with hyper-IgE syndrome [20]. It is not clear whether this phenotype is an epiphenomenon of a systemic immune defect, or whether the skeletal deformities and consequent alterations in lung anatomy and mechanics might impair clearance of bronchial secretions. Increased susceptibility to bronchiectasis and pneumonia has been noted in Marfan's syndrome [84] and hyper-IgE syndrome [85]. Finally, solute carrier 11A1 (SLC11A1) may be relevant in Lady Windermere syndrome; this is discussed in more detail later.

\section{IMPAIRED SYSTEMIC IMMUNITY AND NTMLD}

Since the late 1990s, the molecular basis of susceptibility to mycobacterial disease has become better characterised with the identification of several mutations affecting cell-mediated immunity. Examples are mutations involving IL-12 [48] and IFN- $\gamma$ Rs [86]. Nevertheless, only $35 \%$ of HIV-negative patients with disseminated NTM disease exhibit an identifiable genetic abnormality [20]. Most patients with NTMLD surveyed by HUANG et al. [87] showed no evidence of IFN- $\gamma$ R or SLC11A1 mutations. Granuloma formation appears normal in these patients [88], reflecting intact cell-mediated immunity [89].

\section{Congenital and inherited susceptibility to NTMLD}

The term Mendelian susceptibility to mycobacterial disease [90] denotes those inherited disorders causing an immune defect partly or totally restricted to NTMLD. All disorders classified in this category are caused by mutations in the genes encoding cytokines, receptors and downstream signal-transducing proteins of the IL-12/IFN- $\gamma$ axis. Susceptibility to NTM associated with these conditions is not restricted to lung disease; indeed, most of the NTM infections described in this group have been disseminated or extrapulmonary. However, the literature on these rare disorders is currently confined to case reports and case series [48-54].

A number of genetic defects in the IL-12/IFN- $\gamma /$ STAT1 signalling pathway have been described. Over 150 individuals have been documented with such defects, most of whom were recognised because of recurrent NTM infection [52]. Clinically relevant mutations have been described in the genes encoding IL-12, IL-12R $\beta 1$, IFN- $\gamma$ R1, IFN- $\gamma$ R2 and STAT1 [4, 48, 50, 86]. Mutations have not been described in IFN- $\gamma$ itself, although IFN- $\gamma$ deficiency associated with disseminated $M$. tuberculosis disease has been reported [91].

Most mutations affecting IFN- $\gamma$ R1, IFN- $\gamma$ R2 and STAT1 show an autosomal dominant pattern of inheritance and cause only partial impairment of IFN- $\gamma$ signalling [86]. Recurrent mycobacterial disease first becomes evident in adolescence or adulthood (mean age $13.4 \mathrm{yrs}$ ), and onset appears to be delayed among patients who have received the bacille Calmette-Guérin (BCG) vaccination [86]. Granuloma formation is normal [92]. These patients generally respond to antimycobacterial chemotherapy or exogenous IFN- $\gamma$ [86]. They show increased susceptibility to Salmonella and Histoplasma infections, but retain resistance to viral infection [4].

In contrast, most patients with autosomal recessive mutations affecting IFN- $\gamma$ signalling exhibit a complete absence of IFN- $\gamma$ activity [86]. In the case of recessive STAT1 mutations, activity of other IFNs is also absent, leading to vulnerability to viral infection. Patients with recurrent disseminated infection often present in early childhood and respond poorly to antimicrobial therapy [4,86]. Granulomas are absent or poorly formed and abundant mycobacteria are present in tissues [92]. Occasional success with haematopoietic stem cell transplantation has been reported [93].

Mutations in the gene encoding the 440 subunit of IL-12 lead to deficiency in, or absence of, IL-12. Mutations in the gene encoding the IL-12Rß1 subunit lead to impaired IL-12 signalling. PICARD et al. [48] reported a series of 13 patients with IL-12 deficiency. The phenotype appears to be variable; 12 out of the 13 patients had a history of mycobacterial disease, and all children given BCG inoculation subsequently developed disseminated infection. However, overall mortality with 
IL-12 deficiency was lower than with complete IFN- $\gamma$ R deficiency, and granuloma formation was usually preserved.

The phenotypic abnormality associated with IL-12R $\beta 1$ deficiency is mild. A reported series of affected individuals found an increased incidence of mycobacterial disease (predominantly M. avium), but no cases of recurrent disease and low mortality [50]. FIESCHI et al. [50] speculated that IL-12 might be a redundant part of the immune response against mycobacteria.

\section{Other primary immunodeficiency disorders}

Rare mutations in the NF- $\mathrm{BB}$ essential modulator gene are associated with severe X-linked impairment of innate and adaptive immunity. Such patients are susceptible to a wide range of infections, including those caused by NTM [94]. A French family has been described with an X-linked recessive syndrome characterised by recurrent mycobacterial disease (disseminated BCG infection and TB), with no detectable abnormality of NF- $\kappa B$ essential modulator or the IL-12/IFN- $\gamma$ axis [95].

Chronic granulomatous disease has rarely been associated with NTMLD [55]. X-linked hyper-IgM syndrome has only been associated with susceptibility to TB [96].

\section{Human leukocyte antigen alleles}

Some authors have reported an association between human leukocyte antigens (HLAs) and susceptibility to TB, principally the class I antigens A10 and B8 and the class II antigen DR2 (DRB1*1501) [97]. HLA genotyping of HIV-positive patients with disseminated MAC has revealed positive associations with the DR2, DQB1*0601 and DRB1*0701 alleles, and a negative association with the $\mathrm{DMA}^{*} 0102$ allele [98]. Two Japanese groups have identified HLA antigens including DR6, DQ4, A33 and A26 as being more common among patients with MACLD without pre-existing lung disease [56, 57]; A26 was associated with progression of disease.

\section{CF transmembrane conductance regulator mutations}

Heterozygosity for mutant CF transmembrane conductance regulator (CFTR) is associated with phenotypic manifestations of $\mathrm{CF}$, such as chronic pancreatitis, sinusitis and bronchiectasis [99]. Up to $24 \%$ of patients with CF show evidence of NTMLI [33]. In a study of Kim et al. [61], there was a greater likelihood of radiological NTMLD progression in patients with single CFTR mutations. Some authors have suggested that type 2 NTMLD might be a forme fruste of CF [77]. ZIEDALSKI et al. [59] tested 50 patients with idiopathic bronchiectasis or NTMLD (20 patients in the latter group) for CFTR mutations and elevated sweat chloride concentrations. Of the study group, $50 \%$ were either heterozygous or homozygous for pathological CFTR mutations, and 20\% met diagnostic criteria for CF. In another report, $24 \%$ of patients with NTMLD exhibited at least one CFTR mutation [60].

CFTR mutations are common in Europeans [100], and will become more common as additional rare CFTR alleles are added to the $>1,500$ mutations already described [101]. The clinical relevance of heterozygosity for CFTR alleles largely awaits clarification.

\section{$\alpha_{1}$-Antitrypsin}

There is scant literature supporting an association between $\alpha_{1}$ antitrypsin $\left(\alpha_{1}-\mathrm{AT}\right)$ mutations and NTMLD. KIM et al. [61] compared NTMLD CT features in patients with normal and abnormal $\alpha_{1}$-AT phenotypes and found no differences at diagnosis or during follow-up. KAMINSKA et al. [102] studied patients with bronchiectasis and pulmonary infection with rapidly growing NTM; $31 \%$ exhibited an abnormal $\alpha_{1}$-AT genotype versus $27 \%$ of patients infected with pyogenic bacteria alone ( $p$-value not reported). It is not clear whether $\alpha_{1}$-AT mutations predispose to NTMLD independent of the airways disease associated with $\alpha_{1}$-AT deficiency [103].

\section{SLC11A1: natural resistance-associated macrophage protein 1}

SLC11A1 or natural resistance-associated macrophage protein 1 (NRAMP1) is an ion transporter that localises to the lysosomal membrane during phagocytosis, where it acts as a divalent cation transporter [104]. The published literature suggests an association between some SLC11A1 polymorphisms and NTMLD. KOH et al. [58] compared the prevalence of three SLC11A1 polymorphisms in 41 patients with type 2 NTMLD (with $M$. intracellulare and $M$. abscessus) versus 50 healthy controls. Heterozygosity for the intron 4, codon 543 of exon 15 or 3 '-untranslated region polymorphisms was associated with increased risk of NTMLD, with odds ratios of 2.78, 5.74 and 9.54, respectively. However, the earlier study of eight patients and four controls of HUANG et al. [87] had found no association between SLC11A1 polymorphisms and NTMLD. A metaanalysis found no association between SLC11A1 polymorphisms and TB [105].

\section{Vitamin D receptor polymorphisms}

Vitamin D receptors (VDRs) are expressed on the surface of macrophages and activated lymphocytes. Vitamin D is believed to exert a number of immunomodulatory effects on these cells, including suppression of IFN- $\gamma$ and IL-12 production, with the net effect of favouring the proliferation and activity of Th2 over Th1 [106]. Th1 are thought to produce a cytokine profile that favours granuloma formation and cellmediated immunity, whereas Th2 activity favours humoral immunity [107]. Imbalance between Th1 and Th2 responses has been implicated in the pathogenesis of a variety of immunological and infectious diseases, including asthma [108, 109], atopy [107], ulcerative colitis [110], leishmaniasis [111], TB [112] and leprosy [113].

Several groups have reported associations between VDR polymorphisms and risk of TB [114]. VDR polymorphisms might therefore be expected to affect susceptibility to NTMLD. GELDER et al. [62] tested 56 patients with M. malmoense lung disease for three VDR polymorphisms, and found decreased prevalence of the Flavobacterium okeanokoites I (FokI) f polymorphism and increased prevalence of the Acetobacter pasteuranis subspecies pasteuranis I A and Thermus aquaticus YTI I (TaqI) t polymorphisms. However, TANAKA et al. [115] tested 111 Japanese patients with MACLD and 177 healthy controls for the FokI and TaqI polymorphisms and found no difference in prevalence compared with controls.

Coeliac disease, a chronic inflammatory disorder of the small bowel, has been associated with increased risk of TB (hazard 
ratio 3.74 ) in a Swedish cohort study of 14,335 patients [116] LUDVIGSSON et al. [116] speculate that malabsorption of vitamin $\mathrm{D}$ might provide an explanation. There is no published literature on NTM disease among patients with coeliac disease.

\section{Toll-like receptor 2}

TLRs, human equivalents of the Toll receptor of Drosophila spp., mediate recognition of bacterial antigens by the innate immune system [117]. TLR2 has been identified as the means by which human macrophages recognise mycobacteria [6].

RYU et al. [118] studied 17 patients with NTM lung disease (MAC and M. abscessus), measuring production of TLR2 mRNA, TNF- $\alpha$ mRNA, IL-12 mRNA, TNF- $\alpha$ and the IL-12 p40 subunit by peripheral blood monocytes. After exposure to MAC, the levels of these products produced by monocytes from NTM patients were lower than those produced by monocytes from healthy controls. Exposure to MAC in the presence of neutralising anti-TLR2 antibody reduced the measured production of mRNA and cytokines among controls; there was no reduction observed among NTM patients. These results suggest a defect in TLR2 conferring susceptibility to NTM disease.

\section{ACQUIRED SUSCEPTIBILITY TO NTM \\ HIV}

Disseminated MAC has long been recognised as a complication of AIDS [119]. Interestingly, isolated MACLD is uncommon among HIV-positive patients, even in cases in which the CD4 count is very low [120]. This fact highlights the importance of abnormal airway mucosa as an initiating factor for MACLD.

\section{Malignancy}

The association between cancer and TB is well recognised [121]. Many reports of pulmonary and extrapulmonary NTM disease among patients with solid and haematological malignancies have been published [122-124]. Any association is probably secondary to defective cell-mediated immunity [125]. NTMLD among patients with cancer is uncommon, but the incidence is probably higher than in the general population [73]. JACOBSON et al. [126] found an annual incidence of 2.5 cases of M. kansasii disease per 100,000 patient registrations in an oncology centre in southern USA. The estimated annual incidence among the general population is $1.0-1.8$ per 100,000 population [73]. It is not known whether these infections were triggered by malignancy, antineoplastic chemotherapy, corticosteroids, indwelling vascular catheters or comorbid conditions, such as diabetes mellitus.

Leukaemia is a stronger risk factor than solid malignancy for NTM disease at various sites [126]. Hairy cell leukaemia is the haematological malignancy most strongly associated with NTM disease in the literature [127]. The incidence of mycobacterial disease is $\sim 5 \%$ in this condition [122]. The monocytopenia and impaired monocyte function seen in this disorder may explain this association [123]. There are several reports of NTM disease associated with other acute and chronic leukaemias [124, 128-131].

Infection with rapidly growing mycobacteria occurs among patients with cancer [123, 129, 132-134]. Most are associated with intravenous lines [123].

\section{Organ transplantation}

The literature on NTM disease among solid organ and haematopoietic stem cell transplant (HSCT) recipients has been reviewed by DOUCETTE and FISHMAN [135]. The incidence of NTM disease in HSCT is $0.4-4.9 \%$ [135, 136], and it usually occurs as a vascular-catheter-related infection; however, 30\% of reported cases exhibited pulmonary disease. MAC is the commonest pulmonary pathogen and the commonest pathogen in children [136], whereas rapidly growing mycobacteria are the commonest pathogens overall. Half of all reported cases of NTM disease after HSCT occur in the setting of graftversus-host disease, perhaps because treatment of this condition involves anti-TNF- $\alpha$ antibodies [136].

NTM disease has been reported in heart, lung, liver and kidney transplant recipients. The reported incidences are $0.24-2.8$, $0.46-2.3,<0.1$ and $0.16-0.38 \%$, respectively [135]. Among heart transplant recipients, the incidence may have been higher prior to widespread use of cyclosporin [137]. Renal and heart transplant recipients usually develop cutaneous disease, whereas lung transplant recipients usually develop pleuropulmonary disease. $M$. kansasii is the most common pathogen overall, MAC is most common following lung transplantation and rapidly growing mycobacteria are less important (although still prominent among renal transplant recipients). When NTM are isolated prior to transplantation, the effect on subsequent risk of NTM disease is unknown, but appears to be low in patients whose infection is treated [135, 138].

\section{Diabetes mellitus}

There have been several reports of NTM disease in diabetic patients, including cutaneous infections with $M$. chelonae at insulin injection sites [139-142], MAC pleuritis [143], M. kansasii pneumonia [144], MAC suppurative thyroiditis [145], and flexor tenosynovitis with $M$. kansasii [146] and $M$. scrofulaceum [147, 148]. Several risk factors for NTM disease, such as CF and corticosteroid use, are also risk factors for diabetes. There is no literature regarding diabetes mellitus as an independent risk factor for NTMLD.

\section{Chronic renal failure}

NTM disease associated with catheter exit sites (cutaneous infection and peritonitis) is a recognised complication of peritoneal dialysis [149]. Cases of bone and joint infection associated with slowly growing mycobacteria have also been reported [150, 151]. Chronic renal failure has been identified as a possible risk factor for NTM disease in retrospective cohort studies and literature reviews [23, 134, 152].

\section{TNF- $\alpha$ antagonists}

The TNF- $\alpha$ antagonists include the monoclonal antibodies infliximab and adalimumab and the soluble $\mathrm{TNF}-\alpha$ receptor etanercept. They are effective treatments for many inflammatory disorders, including rheumatoid arthritis and inflammatory bowel disease $[153,154]$. Infliximab and adalimumab are more potent immunosuppressants than etanercept; besides binding to circulating TNF- $\alpha$, they also inhibit lymphocyte activation and IFN- $\gamma$ production [155]. Infliximab also induces apoptosis of immune cells by binding to transmembrane TNF- $\alpha$ [156]. The increased risk of TB associated with TNF- $\alpha$ antagonists is well established [157, 158], and is greater for infliximab than for the 
less potent etanercept [159]. Most cases occur within the first 90 days of treatment and so probably represent reactivation of latent TB infection (LTBI) rather than a primary infection [159].

The literature on NTMLD is more limited. In a review of Food and Drug Administration records of US patients treated with TNF- $\alpha$ antagonists, NTMLD was much less commonly reported than TB (10.7 versus 108.1 cases per 100,000 patients), and was more common for infliximab than for etanercept (rate ratio 2.08; $\mathrm{p}=0.023$ ) [159]. The lower rates of NTMLD may occur because $M$. tuberculosis is more virulent than NTM, or because pre-existing LTBI is more common than subclinical NTMLD among patients treated with TNF- $\alpha$ antagonists.

Etanercept therapy has been reported in association with fatal MACLD [160], fatal pulmonary M. xenopi infection [161], fatal pulmonary $M$. abscessus infection [162], $M$. chelonae endophthalmitis [163], M. xenopi spinal osteomyelitis [164] and pulmonary M. szulgai infection [165]. In the latter case, the patient's treatment changed from etanercept to adalimumab after M. szulgai was identified.

Current guidelines recommend screening for active or inactive $\mathrm{TB}$, and risk assessment for LTBI before commencing TNF- $\alpha$ antagonist therapy [166]. If possible, treatment for LTBI should be completed before starting TNF- $\alpha$ antagonists, so that active TB is not treated with a regimen designed for LTBI. Expert opinion suggests that patients with active NTM disease should only receive TNF- $\alpha$ antagonists with concurrent antimycobacterial chemotherapy [73].

\section{Anti-IFN- $\gamma$ antibodies}

Following several reports of high-affinity neutralising antibodies directed against IFN- $\gamma$ in patients with recurrent mycobacterial infection [167, 168], PATEL et al. [69] reported the results of screening 35 patients with recurrent disseminated NTM disease or NTMLD. Inhibitory IFN- $\gamma$ antibodies were detected in six $(17 \%)$ patients. In vitro tests showed that these antibodies prevented IFN- $\gamma$ from binding to its receptor. PATEL et al. [69] were unable to determine whether these antibodies were pathogenic or simply a consequence of prolonged high titres of circulating IFN- $\gamma$.

\section{Sex hormones}

The prevalence of type 2 NTMLD rises following menopause. Female sex hormones have, therefore, been suggested as protecting against this condition [169]. Both male and female sex hormones exert immunomodulatory effects on murine macrophages. In the study of TsuYUGUCHI et al. [169], ovarectomised mice exhibited a higher mycobacterial load following infection with MAC compared with controls. Macrophages from infected mice exhibited enhanced in vitro activity against MAC when treated with $17 \beta$-oestradiol. The effect of testosterone on susceptibility to NTM is less clear in mice. It induces macrophage apoptosis [170] and slows wound healing [171], but also stimulates macrophage TNF- $\alpha$ production [171]. The role of androgens in mycobacterial infection has not been studied. Finally, CURRAN et al. [172] have reported reduced IFN- $\gamma$ production among MAC-infected mice fed soy or genistein, suggesting that dietary phyto-oestrogens might counteract the antimycobacterial effects of endogenous female sex hormones. There is no literature regarding sex hormones and human susceptibility to mycobacterial disease.

\section{CONCLUSION}

The factors implicated in increased susceptibility to NTMLD have been reviewed. These may be local or systemic, congenital or acquired. NTM usually require abnormal airway mucosa in order to initiate bronchopulmonary infection. Local factors that exacerbate damage to the mucosal surface, or that increase the tissue burden of NTM, may promote disease. These include airway inflammation, ciliary dysfunction, abnormal sputum composition, mucus plugging of large or small airways, and the elongated bronchi and absent collateral ventilation that characterise the RML and lingula.

Some primary immunodeficiency conditions cause increased vulnerability to systemic NTM disease. Hereditary defects in the IL-12/IFN- $\gamma /$ STAT1 axis predispose to disseminated NTM disease. Certain HLA alleles, CFTR alleles, and polymorphisms of SLC11A1 (NRAMP1) and the VDR may increase susceptibility to NTM disease while sparing other aspects of immune function.

It is unclear whether susceptibility to NTMLD may be acquired as an isolated phenomenon; candidate mechanisms include development of anti-IFN- $\gamma$ autoantibodies, waning of endogenous oestrogen levels following menopause and use of dietary phyto-oestrogens. These last two mechanisms have only been investigated in animal models.

Possible causes of type 2 NTMLD and Lady Windermere syndrome may be found within all of the above categories; they include anatomical peculiarities of the RML and lingula, inheritance of certain SLC11A1 or CFTR genetic variants, and the fall in endogenous oestrogen production following menopause.

Important areas for further study include smoking, oral corticosteroid treatment, chronic renal failure, diabetes mellitus and other known risk factors for pulmonary tuberculosis. From a clinical viewpoint, caution is appropriate in managing such patients, and more frequent monitoring and/or lowering the threshold for treatment may be appropriate. Despite new exciting developments, there is much more to be learnt before understanding of the mechanisms and relative importance of factors associated with susceptibility to nontuberculous mycobacterial lung disease is complete.

\section{ACKNOWLEDGEMENTS}

The authors thank M. Empson (Dept of Immunology, Auckland City Hospital, Auckland, New Zealand) for advice during preparation of the present manuscript.

\section{REFERENCES}

1 Runyon EH. Anonymous mycobacteria in pulmonary disease. Med Clin North Am 1959; 43: 273-290.

2 Wolinsky E. Nontuberculous mycobacteria and associated diseases. Am Rev Respir Dis 1979; 119: 107-159.

3 De Groote MA, Huitt G. Infections due to rapidly growing mycobacteria. Clin Infect Dis 2006; 42: 1756-1763.

4 Haverkamp MH, van Dissel JT, Holland SM. Human host genetic factors in nontuberculous mycobacterial infection: 
lessons from single gene disorders affecting innate and adaptive immunity and lessons from molecular defects in interferon- $\gamma$-dependent signaling. Microbes Infect 2006; 8: 1157-1166.

5 Doffinger R, Patel S, Kumararatne DS. Human immunodeficiencies that predispose to intracellular bacterial infections. Curr Opin Rheumatol 2005; 17: 440-446.

6 Underhill DM, Ozinsky A, Smith KD, Aderem A. Tolllike receptor-2 mediates mycobacteria-induced proinflammatory signaling in macrophages. Proc Natl Acad Sci USA 1999; 96: 14459-14463.

7 Schroder K, Hertzog PJ, Ravasi T, Hume DA. Interferon- $\gamma$ : an overview of signals, mechanisms and functions. J Leukoc Biol 2004; 75: 163-189.

8 Boehm U, Klamp T, Groot M, Howard JC. Cellular responses to interferon- $\gamma$. Annu Rev Immunol 1997; 15: 749-795.

9 Jacobs M, Togbe D, Fremond C, et al. Tumor necrosis factor is critical to control tuberculosis infection. Microbes Infect 2007; 9: 623-628.

10 Mutlu GM, Mutlu EA, Bellmeyer A, Rubinstein I. Pulmonary adverse events of anti-tumor necrosis factor$\alpha$ antibody therapy. Am J Med 2006; 119: 639-646.

11 Kindler V, Sappino AP, Grau GE, Piguet PF, Vassalli P. The inducing role of tumor necrosis factor in the development of bactericidal granulomas during BCG infection. Cell 1989; 56: 731-740.

12 Keane J, Gershon S, Wise RP, et al. Tuberculosis associated with infliximab, a tumor necrosis factor $\alpha$ neutralizing agent. N Engl J Med 2001; 345: 1098-1104.

13 Houben EN, Nguyen L, Pieters J. Interaction of pathogenic mycobacteria with the host immune system. Curr Opin Microbiol 2006; 9: 76-85.

14 Falkinham JO 3rd. Epidemiology of infection by nontuberculous mycobacteria. Clin Microbiol Rev 1996; 9: 177215.

15 Fratti RA, Chua J, Vergne I, Deretic V. Mycobacterium tuberculosis glycosylated phosphatidylinositol causes phagosome maturation arrest. Proc Natl Acad Sci USA 2003; 100: 5437-5442.

16 Riley LW. Of mice, men, and elephants: Mycobacterium tuberculosis cell envelope lipids and pathogenesis. J Clin Invest 2006; 116: 1475-1478.

17 Wilson TM, de Lisle GW, Collins DM. Effect of inhA and $k a t G$ on isoniazid resistance and virulence of Mycobacterium bovis. Mol Microbiol 1995; 15: 1009-1015.

18 Walburger A, Koul A, Ferrari G, et al. Protein kinase G from pathogenic mycobacteria promotes survival within macrophages. Science 2004; 304: 1800-1804.

19 Lella RK, Sharma C. Eis (enhanced intracellular survival) protein of Mycobacterium tuberculosis disturbs the cross regulation of T-cells. J Biol Chem 2007; 282: 18671-18675.

20 Guide SV, Holland SM. Host susceptibility factors in mycobacterial infection. Genetics and body morphotype. Infect Dis Clin North Am 2002; 16: 163-186.

21 Witty LA, Tapson VF, Piantadosi CA. Isolation of mycobacteria in patients with pulmonary alveolar proteinosis. Medicine (Baltimore) 1994; 73: 103-109.

22 Corbett EL, Churchyard GJ, Clayton T, et al. Risk factors for pulmonary mycobacterial disease in South African gold miners. A case-control study. Am J Respir Crit Care Med 1999; 159: 94-99.

23 Ergin A, Hascelik G. Non tuberculous mycobacteria (NTM) in patients with underlying diseases: results obtained by using polymerase chain reaction-restriction enzyme analysis between 1997-2002. New Microbiol 2004; 27: 49-53.

24 Fowler SJ, French J, Screaton NJ, et al. Nontuberculous mycobacteria in bronchiectasis: prevalence and patient characteristics. Eur Respir J 2006; 28: 1204-1210.

25 Fujita J, Kishimoto T, Ohtsuki Y, et al. Clinical features of eleven cases of Mycobacterium avium-intracellulare complex pulmonary disease associated with pneumoconiosis. Respir Med 2004; 98: 721-725.

26 Maugein J, Dailloux M, Carbonnelle B, Vincent V, Grosset J. Sentinel-site surveillance of Mycobacterium avium complex pulmonary disease. Eur Respir J 2005; 26: 1092-1096.

27 Morita H, Usami I, Torii M, et al. Isolation of nontuberculous mycobacteria from patients with pneumoconiosis. J Infect Chemother 2005; 11: 89-92.

28 Sonnenberg P, Murray J, Glynn JR, Thomas RG, GodfreyFaussett $P$, Shearer S. Risk factors for pulmonary disease due to culture-positive $M$. tuberculosis or nontuberculous mycobacteria in South African gold miners. Eur Respir J 2000; 15: 291-296.

29 Teo SK, Lo KL. Nontuberculous mycobacterial disease of the lungs in Singapore. Singapore Med J 1992; 33: 464-466.

30 Wickremasinghe M, Ozerovitch LJ, Davies G, et al. Nontuberculous mycobacteria in patients with bronchiectasis. Thorax 2005; 60: 1045-1051.

31 Marras TK, Daley CL. Epidemiology of human pulmonary infection with nontuberculous mycobacteria. Clin Chest Med 2002; 23: 553-567.

32 Reich JM, Johnson RE. Mycobacterium avium complex pulmonary disease presenting as an isolated lingular or middle lobe pattern. The Lady Windermere syndrome. Chest 1992; 101: 1605-1609.

33 Olivier KN, Weber DJ, Wallace RJ Jr, et al. Nontuberculous mycobacteria. I: multicenter prevalence study in cystic fibrosis. Am J Respir Crit Care Med 2003; 167: 828-834.

34 Esther CR Jr, Henry MM, Molina PL, Leigh MW. Nontuberculous mycobacterial infection in young children with cystic fibrosis. Pediatr Pulmonol 2005; 40: 39-44.

35 Fauroux B, Delaisi B, Clement A, et al. Mycobacterial lung disease in cystic fibrosis: a prospective study. Pediatr Infect Dis J 1997; 16: 354-358.

36 Leitritz L, Griese M, Roggenkamp A, Geiger AM, Fingerle V, Heesemann J. Prospective study on nontuberculous mycobacteria in patients with and without cystic fibrosis. Med Microbiol Immunol 2004; 193: 209-217.

37 Mussaffi H, Rivlin J, Shalit I, Ephros M, Blau H. Nontuberculous mycobacteria in cystic fibrosis associated with allergic bronchopulmonary aspergillosis and steroid therapy. Eur Respir J 2005; 25: 324-328.

38 Olivier KN. The natural history of nontuberculous mycobacteria in patients with cystic fibrosis. Paediatr Respir Rev 2004; 5: Suppl A, S213-S216.

39 Torrens JK, Dawkins P, Conway SP, Moya E. Nontuberculous mycobacteria in cystic fibrosis. Thorax 1998; 53: $182-185$. 
40 Aitken ML, Burke W, McDonald G, Wallis C, Ramsey B, Nolan C. Nontuberculous mycobacterial disease in adult cystic fibrosis patients. Chest 1993; 103: 1096-1099.

41 Chalermskulrat W, Sood N, Neuringer IP, et al. Nontuberculous mycobacteria in end stage cystic fibrosis: implications for lung transplantation. Thorax 2006; 61: 507-513.

42 Kilby JM, Gilligan PH, Yankaskas JR, Highsmith WE Jr, Edwards LJ, Knowles MR. Nontuberculous mycobacteria in adult patients with cystic fibrosis. Chest 1992; 102: 70-75.

43 Oliver A, Maiz L, Canton R, Escobar H, Baquero F, GomezMampaso E. Nontuberculous mycobacteria in patients with cystic fibrosis. Clin Infect Dis 2001; 32: 1298-1303.

44 Pierre-Audigier C, Ferroni A, Sermet-Gaudelus I, et al. Age-related prevalence and distribution of nontuberculous mycobacterial species among patients with cystic fibrosis. J Clin Microbiol 2005; 43: 3467-3470.

45 Smith MJ, Efthimiou J, Hodson ME, Batten JC. Mycobacterial isolations in young adults with cystic fibrosis. Thorax 1984; 39: 369-375.

46 Thomson RM, Armstrong JG, Looke DF. Gastroesophageal reflux disease, acid suppression, and Mycobacterium avium complex pulmonary disease. Chest 2007; 131: 1166-1172.

47 Koh WJ, Lee JH, Kwon YS, et al. Prevalence of gastroesophageal reflux disease in patients with nontuberculous mycobacterial lung disease. Chest 2007; 131: 1825-1830.

48 Picard C, Fieschi C, Altare F, et al. Inherited interleukin12 deficiency: IL12B genotype and clinical phenotype of 13 patients from six kindreds. Am J Hum Genet 2002; 70: 336-348.

49 Dorman SE, Holland SM. Mutation in the signaltransducing chain of the interferon-gamma receptor and susceptibility to mycobacterial infection. J Clin Invest 1998; 101: 2364-2369.

50 Fieschi C, Dupuis S, Catherinot E, et al. Low penetrance, broad resistance, and favorable outcome of interleukin 12 receptor $\beta 1$ deficiency: medical and immunological implications. J Exp Med 2003; 197: 527-535.

51 Rosenzweig SD, Dorman SE, Uzel G, et al. A novel mutation in IFN- $\gamma$ receptor 2 with dominant negative activity: biological consequences of homozygous and heterozygous states. J Immunol 2004; 173: 4000-4008.

52 van de Vosse E, Hoeve MA, Ottenhoff TH. Human genetics of intracellular infectious diseases: molecular and cellular immunity against mycobacteria and salmonellae. Lancet Infect Dis 2004; 4: 739-749.

53 Dupuis S, Dargemont C, Fieschi C, et al. Impairment of mycobacterial but not viral immunity by a germline human STAT1 mutation. Science 2001; 293: 300-303.

54 Dupuis S, Jouanguy E, Al-Hajjar S, et al. Impaired response to interferon $\alpha / \beta$ and lethal viral disease in human STAT1 deficiency. Nat Genet 2003; 33: 388-391.

55 Ohga S, Ikeuchi K, Kadoya R, et al. Intrapulmonary Mycobacterium avium infection as the first manifestation of chronic granulomatous disease. J Infect 1997; 34: 147-150.

56 Takahashi M, Ishizaka A, Nakamura $H$, et al. Specific HLA in pulmonary MAC infection in a Japanese population. Am J Respir Crit Care Med 2000; 162: 316-318.
57 Kubo K, Yamazaki Y, Hanaoka M, et al. Analysis of HLA antigens in Mycobacterium avium-intracellulare pulmonary infection. Am J Respir Crit Care Med 2000; 161: 1368-1371.

58 Koh WJ, Kwon OJ, Kim EJ, Lee KS, Ki CS, Kim JW. NRAMP1 gene polymorphism and susceptibility to nontuberculous mycobacterial lung diseases. Chest 2005; 128: 94-101.

59 Ziedalski TM, Kao PN, Henig NR, Jacobs SS, Ruoss SJ. Prospective analysis of cystic fibrosis transmembrane regulator mutations in adults with bronchiectasis or pulmonary nontuberculous mycobacterial infection. Chest 2006; 130: 995-1002.

60 Ehrmantraut ME, Hilligoss DM, Chernick M, Steagall WK, Glasgow CG, Anderson VL. Pulmonary nontuberculous mycobacterial infections are highly associated with mutations in CFTR. Am J Respir Crit Care Med 2003; 167: A708.

61 Kim JS, Tanaka N, Newell JD, et al. Nontuberculous mycobacterial infection: CT scan findings, genotype, and treatment responsiveness. Chest 2005; 128: 3863-3869.

62 Gelder CM, Hart KW, Williams OM, et al. Vitamin D receptor gene polymorphisms and susceptibility to Mycobacterium malmoense pulmonary disease. J Infect Dis 2000; 181: 2099-2102.

63 Fishman JE, Schwartz DS, Sais GJ. Mycobacterium kansasii pulmonary infection in patients with AIDS: spectrum of chest radiographic findings. Radiology 1997; 204: 171-175.

64 Raju B, Schluger NW. Significance of respiratory isolates of Mycobacterium avium complex in HIV-positive and HIV-negative patients. Int J Infect Dis 2000; 4: 134-139.

65 El-Solh AA, Nopper J, Abdul-Khoudoud MR, Sherif SM, Aquilina AT, Grant BJ. Clinical and radiographic manifestations of uncommon pulmonary nontuberculous mycobacterial disease in AIDS patients. Chest 1998; 114: 138-145.

66 Szlavik J, Sarvari C. Pulmonary Mycobacterium xenopi infection in AIDS patients treated with HAART in Hungary. Eur J Clin Microbiol Infect Dis 2003; 22: 701-703.

67 Bankier AA, Stauffer F, Fleischmann D, et al. Radiographic findings in patients with acquired immunodeficiency syndrome, pulmonary infection, and microbiologic evidence of Mycobacterium xenopi. J Thorac Imaging 1998; 13: 282-288.

68 Rigsby MO, Curtis AM. Pulmonary disease from nontuberculous mycobacteria in patients with human immunodeficiency virus. Chest 1994; 106: 913-919.

69 Patel SY, Ding L, Brown MR, et al. Anti-IFN- $\gamma$ autoantibodies in disseminated nontuberculous mycobacterial infections. I Immunol 2005; 175: 4769-4776.

70 Middleton AM, Chadwick MV, Nicholson AG, et al. The role of Mycobacterium avium complex fibronectin attachment protein in adherence to the human respiratory mucosa. Mol Microbiol 2000; 38: 381-391.

71 Middleton AM, Chadwick MV, Nicholson AG, et al. Inhibition of adherence of Mycobacterium avium complex and Mycobacterium tuberculosis to fibronectin on the respiratory mucosa. Respir Med 2004; 98: 1203-1206.

72 Morrissey BM. Pathogenesis of bronchiectasis. Clin Chest Med 2007; 28: 289-296.

73 Griffith DE, Aksamit T, Brown-Elliott BA, et al. An official ATS/IDSA statement: diagnosis, treatment, and prevention 
of nontuberculous mycobacterial diseases. Am J Respir Crit Care Med 2007; 175: 367-416.

74 Prince DS, Peterson DD, Steiner RM, et al. Infection with Mycobacterium avium complex in patients without predisposing conditions. N Engl J Med 1989; 321: 863-868.

75 Griffith DE, Girard WM, Wallace RJ Jr. Clinical features of pulmonary disease caused by rapidly growing mycobacteria. An analysis of 154 patients. Am Rev Respir Dis 1993; 147: 1271-1278.

76 Reich JM, Johnson RE. Mycobacterium avium complex pulmonary disease. Incidence, presentation, and response to therapy in a community setting. Am Rev Respir Dis 1991; 143: 1381-1385.

77 Rubin BK. Did Lady Windermere have cystic fibrosis? Chest 2006; 130: 937-938.

78 Dhillon SS, Watanakunakorn C. Lady Windermere syndrome: middle lobe bronchiectasis and Mycobacterium avium complex infection due to voluntary cough suppression. Clin Infect Dis 2000; 30: 572-575.

79 Wells A, Rahman A, Woodhead M, Hansell D, Pfeffer J, Wilson R. The clinical features of voluntary cough suppression associated with chronic pulmonary suppuration ("atussis nervosa"): a controlled evaluation. Am Rev Respir Dis 1993; 147: A461.

80 Huang JH, Kao PN, Adi V, Ruoss SJ. Mycobacterium avium-intracellulare pulmonary infection in HIV-negative patients without preexisting lung disease: diagnostic and management limitations. Chest 1999; 115: 1033-1040.

81 Bradham RR, Sealy WC, Young WG Jr. Chronic middle lobe infection. Factors responsible for its development. Ann Thorac Surg 1966; 2: 612-616.

82 Iseman MD, Buschman DL, Ackerson LM. Pectus excavatum and scoliosis. Thoracic anomalies associated with pulmonary disease caused by Mycobacterium avium complex. Am Rev Respir Dis 1991; 144: 914-916.

83 Pomerantz M, Denton JR, Huitt GA, Brown JM, Powell LA, Iseman MD. Resection of the right middle lobe and lingula for mycobacterial infection. Ann Thorac Surg 1996; 62: 990-993.

84 Bolande RP, Tucker AS. Pulmonary emphysema and other cardiorespiratory lesions as part of the Marfan abiotrophy. Pediatrics 1964; 33: 356-366.

85 Grimbacher B, Holland SM, Puck JM. Hyper-IgE syndromes. Immunol Rev 2005; 203: 244-250.

86 Dorman SE, Picard C, Lammas D, et al. Clinical features of dominant and recessive interferon $\gamma$ receptor 1 deficiencies. Lancet 2004; 364: 2113-2121.

87 Huang JH, Oefner PJ, Adi V, et al. Analyses of the NRAMP1 and IFN- $\gamma$ R1 genes in women with Mycobacterium avium-intracellulare pulmonary disease. Am J Respir Crit Care Med 1998; 157: 377-381.

88 Tanaka E, Amitani R, Niimi A, Suzuki K, Murayama T, Kuze F. Yield of computed tomography and bronchoscopy for the diagnosis of Mycobacterium avium complex pulmonary disease. Am J Respir Crit Care Med 1997; 155: 2041-2046.

89 Epstein WL, Fukuyama K. Mechanisms of granulomatous inflammation. Immunol Ser 1989; 46: 687-721.

90 Johns Hopkins University. Online Mendelian Inheritance in Man. Atypical mycobacteriosis, familial. www.ncbi. nlm.nih.gov/entrez/dispomim.cgi?id=209950 Date last updated: February 27, 2006. Date last accessed: April 10,2008

91 Seneviratne SL, Doffinger R, Macfarlane J, et al. Disseminated Mycobacterium tuberculosis infection due to interferon $\gamma$ deficiency. Response to replacement therapy. Thorax 2007; 62: 97-99.

92 Jouanguy E, Lamhamedi-Cherradi S, Altare F, et al. Partial interferon-gamma receptor 1 deficiency in a child with tuberculoid bacillus Calmette-Guérin infection and a sibling with clinical tuberculosis. J Clin Invest 1997; 100: 2658-2664.

93 Roesler J, Horwitz ME, Picard C, et al. Hematopoietic stem cell transplantation for complete IFN- $\gamma$ receptor 1 deficiency: a multi-institutional survey. J Pediatr 2004; 145: 806-812.

94 Doffinger R, Smahi A, Bessia C, et al. X-linked anhidrotic ectodermal dysplasia with immunodeficiency is caused by impaired NF- $\kappa$ B signaling. Nat Genet 2001; 27: 277-285.

95 Bustamante J, Picard C, Fieschi C, et al. A novel X-linked recessive form of Mendelian susceptibility to mycobacterial disease. J Med Genet 2007; 44: e65.

96 Ito I, Ishida T, Hashimoto T, et al. Hyper-IgM syndrome with systemic tuberculosis. Scand I Infect Dis 2002; 34 305-307.

97 Bellamy R. Genetics and pulmonary medicine. 3. Genetic susceptibility to tuberculosis in human populations. Thorax 1998; 53: 588-593.

98 Naik E, LeBlanc S, Tang J, Jacobson LP, Kaslow RA. The complexity of HLA class II (DRB1, DQB1, DM) associations with disseminated Mycobacterium avium complex infection among HIV-1-seropositive whites. I Acquir Immune Defic Syndr 2003; 33: 140-145.

99 Noone PG, Knowles MR. "CFTR-opathies": disease phenotypes associated with cystic fibrosis transmembrane regulator gene mutations. Respir Res 2001; 2: 328-332.

100 Grody WW, Cutting GR, Klinger KW, Richards CS, Watson MS, Desnick RJ. Laboratory standards and guidelines for population-based cystic fibrosis carrier screening. Genet Med 2001; 3: 149-154.

101 Cystic Fibrosis Genetic Analysis Consortium. Cystic Fibrosis Mutation Database. www.genet.sickkids.on.ca/ cftr Date last updated: March 2, 2007. Date last accessed: December 17, 2007.

102 Kaminska AM, Huitt GA, Fulton KE, Worthen GS, Iseman MD, Chan ED. Prevalence of alpha-1-antitrypsin (AAT) mutations in 100 bronchiectatic patients with rapid-growing mycobacterial (RGM) infections. Am J Respir Crit Care Med 2003; 167: A708.

103 Cuvelier A, Muir JF, Hellot MF, et al. Distribution of $\alpha_{1^{-}}$ antitrypsin alleles in patients with bronchiectasis. Chest 2000; 117: 415-419.

104 Searle S, Bright NA, Roach TI, et al. Localisation of Nramp1 in macrophages: modulation with activation and infection. J Cell Sci 1998; 111: 2855-2866.

105 Li HT, Zhang TT, Zhou YQ Huang QH, Huang J. SLC11A1 (formerly NRAMP1) gene polymorphisms and tuberculosis susceptibility: a meta-analysis. Int $J$ Tuberc Lung Dis 2006; 10: 3-12.

106 DeLuca HF. Overview of general physiologic features and functions of vitamin D. Am J Clin Nutr 2004; 80: Suppl. 6, 1689S-1696S. 
107 Del Prete G. Human Th1 and Th2 lymphocytes: their role in the pathophysiology of atopy. Allergy 1992; 47: 450-455.

108 Robinson DS, Hamid Q, Ying S, et al. Predominant TH2like bronchoalveolar T-lymphocyte population in atopic asthma. N Engl J Med 1992; 326: 298-304.

109 Larche M, Robinson DS, Kay AB. The role of $\mathrm{T}$ lymphocytes in the pathogenesis of asthma. I Allergy Clin Immunol 2003; 111: 450-463.

110 Heller F, Florian P, Bojarski C, et al. Interleukin-13 is the key effector Th2 cytokine in ulcerative colitis that affects epithelial tight junctions, apoptosis, and cell restitution. Gastroenterology 2005; 129: 550-564.

111 Pirmez C, Yamamura M, Uyemura K, Paes-Oliveira M, Conceicao-Silva F, Modlin RL. Cytokine patterns in the pathogenesis of human leishmaniasis. J Clin Invest 1993; 91: 1390-1395.

112 Lienhardt C, Azzurri A, Amedei A, et al. Active tuberculosis in Africa is associated with reduced Th1 and increased Th2 activity in vivo. Eur J Immunol 2002; 32: 1605-1613.

113 Modlin RL. Th1-Th2 paradigm: insights from leprosy. $J$ Invest Dermatol 1994; 102: 828-832.

114 Lewis SJ, Baker I, Davey Smith G. Meta-analysis of vitamin $\mathrm{D}$ receptor polymorphisms and pulmonary tuberculosis risk. Int J Tuberc Lung Dis 2005; 9: 1174-1177.

115 Tanaka G, Shojima J, Matsushita I, et al. Pulmonary Mycobacterium avium complex infection: association with NRAMP1 polymorphisms. Eur Respir J 2007; 30: 1376-1382.

116 Ludvigsson JF, Wahlstrom J, Grunewald J, Ekbom A, Montgomery SM. Coeliac disease and risk of tuberculosis: a population based cohort study. Thorax 2007; 62: 23-28.

117 Medzhitov R, Preston-Hurlburt P, Janeway CA Jr. A human homologue of the Drosophila Toll protein signals activation of adaptive immunity. Nature 1997; 388: 394-397.

118 Ryu YJ, Kim EJ, Lee SH, et al. Impaired expression of tolllike receptor 2 in nontuberculous mycobacterial lung disease. Eur Respir J 2007; 30: 736-742.

119 Horsburgh CR Jr, Selik RM. The epidemiology of disseminated nontuberculous mycobacterial infection in the acquired immunodeficiency syndrome (AIDS). Am Rev Respir Dis 1989; 139: 4-7.

120 Salama C, Policar M, Venkataraman M. Isolated pulmonary Mycobacterium avium complex infection in patients with human immunodeficiency virus infection: case reports and literature review. Clin Infect Dis 2003; 37: e35-e40.

121 Targeted tuberculin testing and treatment of latent tuberculosis infection, Am J Respir Crit Care Med 2000; 161: S221-S247.

122 Bennett C, Vardiman J, Golomb H. Disseminated atypical mycobacterial infection in patients with hairy cell leukemia. Am J Med 1986; 80: 891-896.

123 Graham JC, Tweddle DA, Jenkins DR, Pollitt C, Pedler SJ. Non-tuberculous mycobacterial infection in children with cancer. Eur J Clin Microbiol Infect Dis 1998; 17: 394-397.

124 Levendoglu-Tugal O, Munoz J, Brudnicki A, Fevzi Ozkaynak M, Sandoval C, Jayabose S. Infections due to nontuberculous mycobacteria in children with leukemia. Clin Infect Dis 1998; 27: 1227-1230.
125 Allen UD. Factors influencing predisposition to sepsis in children with cancers and acquired immunodeficiencies unrelated to human immunodeficiency virus infection. Pediatr Crit Care Med 2005; 6: Suppl. 3, S80-S86.

126 Jacobson KL, Teira R, Libshitz HI, et al. Mycobacterium kansasii infections in patients with cancer. Clin Infect Dis 2000; 31: 628-631.

127 Thaker H, Neilly IJ, Saunders PG, Magee JG, Snow MH, Ong EL. Remember mycobacterial disease in hairy cell leukaemia (HCL). J Infect 2001; 42: 213-214.

128 Krebs T, Zimmerli S, Bodmer T, Lammle B. Mycobacterium genavense infection in a patient with longstanding chronic lymphocytic leukaemia. J Intern Med 2000; 248: 343-348.

129 Rolston KV, Jones PG, Fainstein V, Bodey GP. Pulmonary disease caused by rapidly growing mycobacteria in patients with cancer. Chest 1985; 87: 503-506.

130 Suryanarayan K, Campbell J, Eskenazi AE. Nontuberculous mycobacterial infections in pediatric acute leukemia. J Pediatr Hematol Oncol 2002; 24: 558-560.

131 Unni M, Jesudason MV, Rao S, George B. Mycobacterium fortuitum bacteraemia in an immunocompromised patient. Ind J Med Microbiol 2005; 23: 137-138.

132 Robinson H, Smith S. Mycobacterium fortuitum infection in a patient with chronic lymphocytic leukaemia. $\mathrm{Br} J$ Haematol 2004; 127: 126.

133 Wallace RJ Jr, Swenson JM, Silcox VA, Good RC, Tschen JA, Stone MS. Spectrum of disease due to rapidly growing mycobacteria. Rev Infect Dis 1983; 5: 657-679.

134 Ingram CW, Tanner DC, Durack DT, Kernodle GW Jr, Corey GR. Disseminated infection with rapidly growing mycobacteria. Clin Infect Dis 1993; 16: 463-471.

135 Doucette K, Fishman JA. Nontuberculous mycobacterial infection in hematopoietic stem cell and solid organ transplant recipients. Clin Infect Dis 2004; 38: 1428-1439.

136 Nicholson O, Feja K, LaRussa P, et al. Nontuberculous mycobacterial infections in pediatric hematopoietic stem cell transplant recipients: case report and review of the literature. Pediatr Infect Dis J 2006; 25: 263-267.

137 Novick RJ, Moreno-Cabral CE, Stinson EB, et al. Nontuberculous mycobacterial infections in heart transplant recipients: a seventeen-year experience. J Heart Transplant 1990; 9: 357-363.

138 Kesten S, Chaparro C. Mycobacterial infections in lung transplant recipients. Chest 1999; 115: 741-745.

139 Finucane K, Ambrey P, Narayan S, Archer CB, Dayan C. Insulin injection abscesses caused by Mycobacterium chelonae. Diabetes Care 2003; 26: 2483-2484.

140 Jackson PG, Keen H, Noble CJ, Simmons NA. Injection abscesses in a diabetic due to Mycobacterium chelonei var abscessus. BMJ 1980; 281: 1105-1106.

141 Kelly SE. Multiple injection abscesses in a diabetic caused by Mycobacterium chelonei. Clin Exp Dermatol 1987; 12: 48-49.

142 Schadlow M, Laochumroonvorapong P, Burack L, Wu H, Sinha AA. Nodules on the arm of a diabetic patient. Arch Dermatol 2003; 139: 93-98.

143 Nagaia T, Akiyama M, Mita Y, Tomizawa T, Dobashi K, Mori M. Mycobacterium avium complex pleuritis accompanied by diabetes mellitus. Diabetes Res Clin Pract 2000; 48: 99-104. 
144 Arend SM, Cerda de Palou E, de Haas P, et al. Pneumonia caused by Mycobacterium kansasii in a series of patients without recognised immune defect. Clin Microbiol Infect 2004; 10: 738-748.

145 Robillon JF, Sadoul JL, Guerin P, et al. Mycobacterium avium intracellulare suppurative thyroiditis in a patient with Hashimoto's thyroiditis. J Endocrinol Invest 1994; 17: 133-134.

146 Southern PM Jr. Tenosynovitis caused by Mycobacterium kansasii associated with a dog bite. Am J Med Sci 2004; 327: 258-261.

147 Carter TI, Frelinghuysen P, Daluiski A, Brause BD, Wolfe SW. Flexor tenosynovitis caused by Mycobacterium scrofulaceum: case report. I Hand Surg [Am] 2006; 31: 1292-1295.

148 Phoa LL, Khong KS, Thamboo TP, Lam KN. A case of Mycobacterium scrofulaceum osteomyelitis of the right wrist. Ann Acad Med Singapore 2000; 29: 678-681.

149 Rho M, Bia F, Brewster UC. Nontuberculous mycobacterial peritonitis in peritoneal dialysis patients. Semin Dial 2007; 20: 271-276.

150 Kelly M, Thibert L, Sinave C. Septic arthritis in the knee due to Mycobacterium xenopi in a patient undergoing hemodialysis. Clin Infect Dis 1999; 29: 1342-1343.

151 Otaki Y, Nakanishi T, Nanami M, et al. A rare combination of sites of involvement by Mycobacterium intracellulare in a hemodialysis patient: multifocal synovitis, spondylitis, and multiple skin lesions. Nephron 2002; 92: 730-734.

152 Wallace RJ Jr, Brown BA, Onyi GO. Skin, soft tissue, and bone infections due to Mycobacterium chelonae chelonae: importance of prior corticosteroid therapy, frequency of disseminated infections, and resistance to oral antimicrobials other than clarithromycin. J Infect Dis 1992; 166: 405-412.

153 St Clair EW, Wagner CL, Fasanmade AA, et al. The relationship of serum infliximab concentrations to clinical improvement in rheumatoid arthritis: results from ATTRACT, a multicenter, randomized, double-blind, placebo-controlled trial. Arthritis Rheum 2002; 46: 1451-1459.

154 Hanauer SB, Feagan BG, Lichtenstein GR, et al. Maintenance infliximab for Crohn's disease: the ACCENT I randomised trial. Lancet 2002; 359: 1541-1549.

155 Saliu OY, Sofer C, Stein DS, Schwander SK, Wallis RS. Tumor-necrosis-factor blockers: differential effects on mycobacterial immunity. J Infect Dis 2006; 194: 486-492.

156 Scallon BJ, Moore MA, Trinh H, Knight DM, Ghrayeb J. Chimeric anti-TNF- $\alpha$ monoclonal antibody cA2 binds recombinant transmembrane TNF- $\alpha$ and activates immune effector functions. Cytokine 1995; 7: 251-259.

157 Brassard P, Kezouh A, Suissa S. Antirheumatic drugs and the risk of tuberculosis. Clin Infect Dis 2006; 43: 717-722.

158 Wolfe F, Michaud K, Anderson J, Urbansky K. Tuberculosis infection in patients with rheumatoid arthritis and the effect of infliximab therapy. Arthritis Rheum 2004; 50: 372-379.
159 Wallis RS, Broder MS, Wong JY, Hanson ME, Beenhouwer DO. Granulomatous infectious diseases associated with tumor necrosis factor antagonists. Clin Infect Dis 2004; 38: 1261-1265.

160 Jaffery SH, Carrillo M, Betensley AD. Fatal pulmonary nontuberculous mycobacterial infection in a patient receiving etanercept for rheumatoid arthritis. Chest 2004; 126: 944S-945S.

161 Maimon N, Brunton J, Chan AK, Marras TK. Fatal pulmonary Mycobacterium xenopi in a patient with rheumatoid arthritis receiving etanercept. Thorax 2007 62: 739-740.

162 Thomas JE, Taoka CR, Gibbs BT, Fraser SL. Fatal pulmonary Mycobacterium abscessus infection in a patient using etanercept. Hawaii Med J 2006; 65: 12-15.

163 Stewart MW, Alvarez S, Ginsburg WW, Shetty R, McLain WC, Sleater JP. Visual recovery following Mycobacterium chelonae endophthalmitis. Ocul Immunol Inflamm 2006; 14: 181-183.

164 Yim K, Nazeer SH, Kiska D, Rose FB, Brown D, Cynamon $\mathrm{MH}$. Recurrent Mycobacterium xenopi infection in a patient with rheumatoid arthritis receiving etanercept. Scand J Infect Dis 2004; 36: 150-154.

165 van Ingen J, Boeree $M$, Janssen $M$, et al. Pulmonary Mycobacterium szulgai infection and treatment in a patient receiving anti-tumor necrosis factor therapy. Nat Clin Pract Rheumatol 2007; 3: 414-419.

166 British Thoracic Society Standards of Care Committee. BTS recommendations for assessing risk and for managing Mycobacterium tuberculosis infection and disease in patients due to start anti-TNF- $\alpha$ treatment. Thorax 2005; 60: 800-805.

167 Hoflich C, Sabat R, Rosseau S, et al. Naturally occurring anti-IFN- $\gamma$ autoantibody and severe infections with Mycobacterium cheloneae and Burkholderia cocovenenans. Blood 2004; 103: 673-675.

168 Doffinger R, Helbert MR, Barcenas-Morales G, et al Autoantibodies to interferon- $\gamma$ in a patient with selective susceptibility to mycobacterial infection and organspecific autoimmunity. Clin Infect Dis 2004; 38: e10-e14.

169 Tsuyuguchi K, Suzuki K, Matsumoto H, Tanaka E, Amitani R, Kuze F. Effect of oestrogen on Mycobacterium avium complex pulmonary infection in mice. Clin Exp Immunol 2001; 123: 428-434.

170 Cutolo M, Capellino S, Montagna P, Ghiorzo P, Sulli A, Villaggio B. Sex hormone modulation of cell growth and apoptosis of the human monocytic/macrophage cell line. Arthritis Res Ther 2005; 7: R1124-R1132.

171 Ashcroft GS, Mills SJ. Androgen receptor-mediated inhibition of cutaneous wound healing. I Clin Invest 2002; 110: 615-624.

172 Curran EM, Judy BM, Newton LG, et al. Dietary soy phytoestrogens and $\mathrm{ER} \alpha$ signalling modulate interferon gamma production in response to bacterial infection. Clin Exp Immunol 2004; 135: 219-225. 